purveyors of such jargon, another buzz phrase provides the opportunity; the now widespread use of the introductory summative words "at the end of the day" suggests that the important conclusions occur mainly in the evening.

\section{Coping strategies}

Bergman's wish for a moratorium on meetings was, in retrospect, quixotic. However, some strategies for meetings may minimise their impact on real work. These might include conducting meetings standing up in hallways, as it is often in the corridors of power that true decisions are made. Meetings should not occur until after lunch, so people can get some reflective or clinical work done at the beginning of the day. The minimum unit of measurement for a meeting should be reduced from an hour to 15 minutes, given the natural tendency of meetings to fill the available time. Meetings should be for interactions, not for presentations; people can prepare for meetings by reading the material and deciding if they really need to be there, rather than discovering by attending that they did not need to do so. People who chair meetings and lose control of the agenda and the duration should have this reflected in their performance appraisal. Finally, leaders should tally monthly the amount of time they spend in meetings and then ask themselves soberly if this is the optimal use of their time and talents.

We are profoundly unlikely to revert to the pre-corporate era of health care. Healthcare workers who aspire to positions of leadership in healthcare institutions feel increasingly naked without at least an executive MBA degree if not the real McCoy. Or perhaps this is the adolescence of our business evolution, where we eagerly adopt the fashion in the belief that it has deeper meaning and is the only way to be accepted in academic high society. Watch this space in a decade for a fashion update.

Competing interests: None declared.

1 Bergman AB. Meeting mania. N Engl J Med 1994;330:1622-3.

2 Tufte ER. The cognitive style of PowerPoint. Cheshire, CT: Graphics Press LLC, 2003.

\title{
How to get your paper rejected
}

These days, if you do not publish, you perish. Well, you don't perish, but you do not get promotions. With promotions come more responsibilities, more paperwork, more income tax. If you want to stay comfortably in your position, you should not publish. Here are a few tips to get your papers eternally rejected. Proving the efficacy of the method, this article was rejected by the Lancet on 14 May 2004, by the New England Journal of Medicine on 19 May 2004, by JAMA on 27 May 2004, by Science on 24 June 2004, by the Proceedings of the National Academy of Sciences of the United States of America on 29 June 2004, and by Nature on 30 June 2004. Getting started

Start by looking at your data randomly. Something will come out. Why bother with writing a protocol when you already have results?

Be imaginative when writing the title. Put marketing before science. Attract the reader with the promise of an answer you don't have.

Use fancy words.

\section{Questions and answers}

In the abstract, ask as many questions as you can. Show them how broad your interests are.

Come up with a creative answer to a question, any question.

Answers always look nice.

In the introduction, criticise the work of possible reviewers. Be particularly nasty. This is your chance for revenge.

Do a very extensive discussion of the literature in the introduction. They may not like your results, but they may publish it as a review.

Use more fancy words.

As for the materials and methods, sample size calculation is an imperfect science. Calculate the sample size needed based in the size of your sample.

\section{Descriptions}

Describe your methods in random order. Who cares, as long as all the information is there.

Do not describe your methods in detail. The readers of major journals should know better what you are talking about.

Be careful not to give many details. The section will be confusing, and if somebody repeats your experiments he or she may get a different result. You do not have time for controversy.

Use even more fancy words.
Show every single result that you have obtained (or found in the records, actually). Show how thorough you have been in your search for data.

Again, describe your results in random order. You may order them alphabetically.

Have your 4 year old daughter proofread your spelling, and your 2 year old son proofread the grammar.

\section{What you know}

Critically discuss your results, comparing them with others'. I mean being critical of others. This is your second chance for revenge.

You know your conclusions make sense. Do not bother with explaining why.

You know your data are good. You have spent a lot of time copying those darn numbers from the charts. They should support your conclusions.

You know that results often tell more than what is evident. Feel free to draw imaginative conclusions.

\section{The right answer}

What you think is obviously the answer, must be the right answer. Do not look for alternative explanations that will make everything even more confusing.

List references, many references. Copy references from other papers. Do not bother reading the actual articles. If they are published, they have to be accurate.

Do not bother following the journal style for references. You can always change that later.

Add five or six charts. Better still, put in several tables cluttered with numbers. That way, you make sure that nobody will read them.

\section{A work of art}

Do not revise your paper. Think of it as a work of art, that is how it came out of your brain in the first place.

And, finally, my best advice of all:

Get the name of the editor in chief wrong-or get it right, but misspell it.

Horacio Plotkin assistant professor of paediatrics and orthopaedics, University of Nebraska Medical Center, Omaha, USA

(hplotkin@unmc.edu) 